\title{
Impact of increased inflammation biomarkers on periprocedural myocardial infarction in patients undergoing elective percutaneous coronary intervention: a cohort study
}

\author{
Liding Zhao ${ }^{1,2 \#}$, Ya $\mathrm{Li}^{1,2 \#}$, Tian $\mathrm{Xu}^{1,2 \#}$, Yi Luan ${ }^{1,2}$, Qingbo $\mathrm{Lv}^{1,2}$, Yao Wang ${ }^{1,2}$, Xue $\mathrm{Lv}^{1,2}$, Guosheng Fu ${ }^{1,2}$, \\ Wenbin Zhang ${ }^{1,2} \wedge$ \\ ${ }^{1}$ Department of Cardiovascular Diseases, Sir Run Run Shaw Hospital, College of Medicine, Zhejiang University, Hangzhou, China; ${ }^{2}$ Key Laboratory \\ of Cardiovascular Intervention and Regenerative Medicine of Zhejiang Province, Hangzhou, China \\ Contributions: (I) Conception and design: W Zhang, L Zhao; (II) Administrative support: W Zhang, G Fu; (III) Provision of study materials or \\ patients: Y Li, Y Luan, T Xu; (IV) Collection and assembly of data: L Zhao, Q Lv, T Xu; (V) Data analysis and interpretation: L Zhao, Y Wang, X \\ Lv, T Xu; (VI) Manuscript writing: All authors; (VII) Final approval of manuscript: All authors. \\ \#These authors contributed equally to this work. \\ Correspondence to: Wenbin Zhang, MD, PhD. Sir Run Run Shaw Hospital, College of Medicine, Zhejiang University, No. 3 East of Qingchun Road, \\ Hangzhou 310000, China. Email: 3313011@zju.edu.cn.
}

Background: The fact that each inflammatory indicator has a forecasting capacity on the occurrence of periprocedural myocardial infarction (PMI) has a controversial existence. The purpose of this study was to explore the role of inflammation biological indicators on PMI in a group of patients undergoing selective percutaneous coronary intervention (PCI).

Methods: The study was carried out both in a retrospective and prospective manner in 7,413 and 1,189 subjects, respectively. In the retrospective cohort study, the association between inflammation biomarkers and PMI was assessed by univariate and multivariate logistic regression. WBC, CRP, and NLR were distributed using k-means clustering into a virtual variable "Inflammatory Trend", and multivariate logistic regression and subgroup analysis were performed. In the prospective cohort study, the endpoints were PMI, cardiovascular death or cardiac arrest. The chi-square test was performed to calculate the relative risk (RR).

Results: In the retrospective cohort study, except WBC, CRP, NLR and virtual variable "Inflammatory trend" were independent risk factors for PMI. The subgroup analysis revealed that CRP can serve as the most stable predictor. In the prospective cohort study, WBC $(\mathrm{RR}=1.134, \mathrm{P}=0.416)$ has no effect on the incidence of PMI. However, an elevation in the incidence of PMI was observed with an increase of NLR $(\mathrm{RR}=1.354, \mathrm{P}=0.041)$ and $\mathrm{CRP}(\mathrm{RR}=1.412, \mathrm{P}=0.025)$.

Conclusions: In patients with elective PCI for single-vessel lesions, high CRP increases the risk for PMI. The increase of NLR was an independent risk factor for PMI, especially for patients with hypertension and under the age of 70. WBC has no influence on the occurrence of PMI.

Keywords: White blood cell (WBC); periprocedural myocardial infarction (PMI); neutrophil to lymphocyte ratio; C-reactive protein; percutaneous coronary intervention (PCI)

Submitted Apr 08, 2020. Accepted for publication Sep 10, 2020.

doi: $10.21037 /$ jtd-20-1605

View this article at: http://dx.doi.org/10.21037/jtd-20-1605

\footnotetext{
$\wedge$ ORCID: 0000-0003-4746-9570.
} 


\section{Introduction}

Percutaneous coronary intervention (PCI), is considered as one of the main strategies to solve the coronary atherosclerotic heart disease problems (1). Technological developments, effective antithrombotic therapies, and advanced instrumentations have greatly improved the prognosis (2) but also increased the overall complexity of the process.

The occurrence of periprocedural myocardial infarction (PMI) may be related to the long-term increase in allcause mortality (3). Depending upon the diagnostic criteria and the local practice it varies between 5-40\% (4,5). CRP has been shown, in patients under PCI with drug-eluting stent implantation, to be associated with the unsatisfactory occurrence of cardiac events after surgery (6-8). However, four out of the six studies suggested a positive correlation between CRP and PMI while the other two suggested no relationship (8-11). Furthermore, white blood cell (WBC) count and neutrophil to lymphocyte ratio (NLR) have been shown to have a connection with the extent and prognosis of coronary artery diseases (CAD) $(9,10,12-14)$ as well as the incidence of PMI (15) while another study suggested that WBC is not a risk factor of PMI (16) As for NLR, some studies have reported that its increase is connected to the elevated risk of PMI in patients undergoing nonurgent PCI, especially for values $\geq 3$ (15), but Bressi et al. demonstrated that there was no relationship between preprocedural NLR values and the PMI incidence (17). There are several clinic indicators that reflect the inflammatory state of the patient and fact that each biomarker can predict the incidence of PMI is controversial and needs further assessment.

This study aimed to evaluate the predictive value of NLR, WBC, and CRP on PMI through retrospective as well as prospective cohort studies.

We present the following article in accordance with the STROBE reporting checklist (available at http://dx.doi. org/10.21037/jtd-20-1605).

\section{Methods}

This study is a single-center cohort study conducted at Sir Run Run Shaw Hospital, including retrospective and prospective parts. The retrospective study was approved by the Ethics Committee of Sir Run Run Shaw Hospital (NO.20200224-33), and the prospective study was registered at the Chinese Clinical Trial Registry(chiCTR-
RPC-17014094), and informed consent was obtained from all patients. The study was conducted in accordance with the Declaration of Helsinki (as revised in 2013).

\section{Population and procedures}

Patients undergoing elective single coronary artery PCI at Sir Run Run Shaw Hospital between December 2009 to December 2017 were included in the retrospective cohort study. Additional details about the study subjects are listed in Figure 1. The prospective study group included a total of 3726 consecutive patients who underwent an elective single coronary artery PCI between January 2018 to April 2019 and finally 1,189 patients were enrolled in this study. Patient inclusion criteria were (I) patients with elective singlebranch coronary PCI; (II) normal baseline myocardial enzyme level and cTnI measured at 8, 16, 24 and 48 hours after PCI; (III) availability of preprocedural NLR, CRP, and WBC. Exclusion criteria for the patients were (I) revascularization of more than one main coronary artery during single PCI procedure; (II) no stent implantation; (III) patients with severe heart failure, defined by $\mathrm{EF}<45 \%$ or NT-pro BNP >2,000 pg/mL; (IV) patients with chronic total occlusion or undergoing treatment with cutting balloon angioplasty or percutaneous transluminal coronary rotational ablation; (V) patients recovering from acute myocardial infarction (MI); (VI) patient with one of the periprocedural complications such as thrombosis, coronary artery perforation or dissection; (VII) CRP $>10.0 \mathrm{mg} / \mathrm{L}$.

PCI was performed as per the current general guidelines. Before elective single coronary artery PCI, all patients received aspirin plus ticagrelor or clopidogrel at a loading dose of 300, 180, and $300 \mathrm{mg}$, respectively. Periprocedural anticoagulation and antiplatelet therapy were performed as per the standard regimen before PCI. The types of stents, implantation techniques, and the use of intravascular ultrasound (IVUS), optical coherence tomography (OCT) and fractional flow reserve (FFR) were determined by the operators.

For all the patients, NLR, CRP, and WBC were measured within 24 hours before PCI. The levels of myonecrotic markers (cTnI) were measured before and at 8, 16, 24- and 48-hour' time points after PCI. Complete blood counts were measured using a MEK-6458 automated analyzer (Nihon Kohden). CRP levels were measured with a fully automated enzyme-linked immunoassay using an Aeroset 2.0 analyzer (Abbott Diagnostics, Santa Clara, CA, USA). cTnI was measured using the ultrasensitive Singulex 


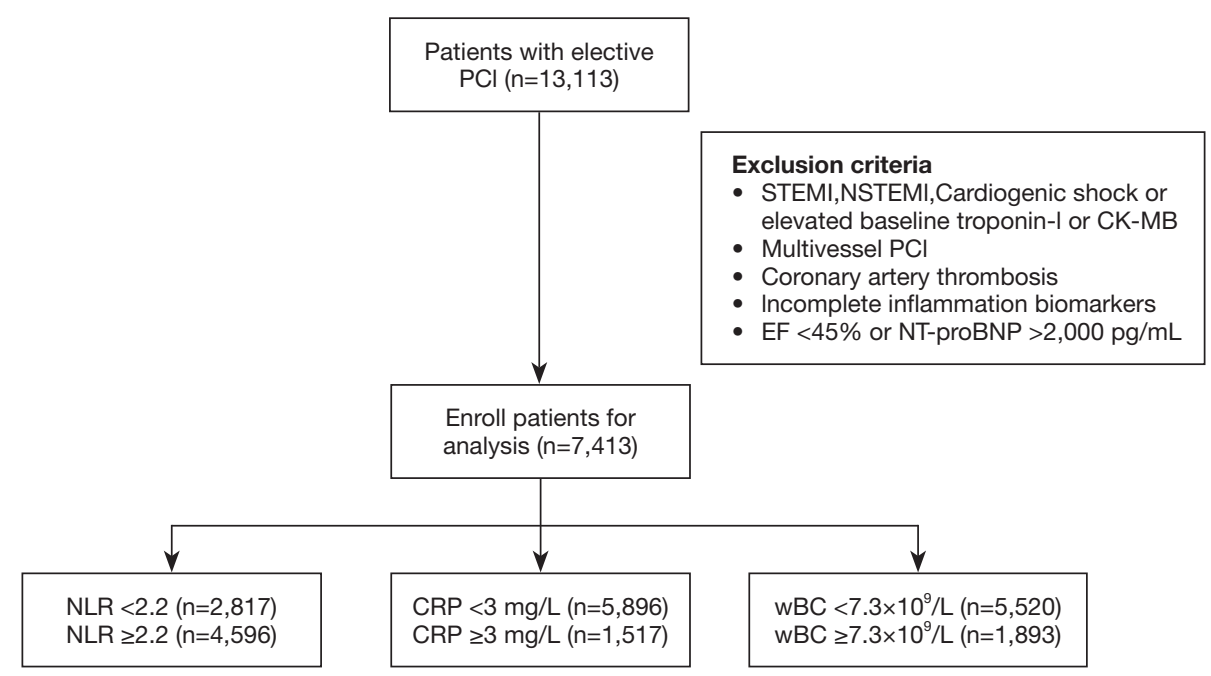

Figure 1 Flow chart for patient inclusion in retrospective cohort study. PCI, percutaneous coronary intervention; STEMI, ST segment Elevation Myocardial Infarction; NSTEMI, non-ST segment Elevation Myocardial Infarction; CK-MB, creatine phosphokinase MB; EF, ejection fraction; NT-proBNP, N-terminal pro-brain natriuretic peptide; CRP, C-reactive protein; WBC, white blood cell; NLR, neutrophil to lymphocyte ratio.

Erenna System (at Singulex, Inc., Berkeley, CA, USA). Different parameters such as a peri-procedural myocardial enzyme, patient demographics, clinical manifestations, angiographic and procedural characteristics were collected from hospital information system.

\section{Sample size}

The sample size calculation was based on previous studies that investigated the correlation between inflammation biomarkers and PMI, and prognosis after PCI. Significant correlations were observed in the retrospective studies that included no more than 4,500 patients $(15,18,19)$ and in the prospective studies that included no more than 100 patients (20). We therefore aimed at including at least 5,000 patients in retrospective research and 150 patients in prospective research during this study.

\section{Definition of PMI, and other definitions}

There have been several investigations for defining an appropriate criterion for PMI $(21,22)$ and these guidelines are being continuously updated (23-26). In this study, PMI was defined as an elevated concentration of $\mathrm{c} T \mathrm{TnI}>5 \times$ URL along with a normal baseline range 48 hours after the procedure (23). Define $W B C \geq 7.3 \times 10^{9} / \mathrm{L}, \mathrm{CRP} \geq 3.0 \mathrm{mg} / \mathrm{L}$, NLR $\geq 2.2$ as exposures. The blood pressure of patients with hypertension was kept below 140/90 mmHg and HbA1c of patients with diabetes mellitus was kept at $<6.5 \%$. Estimated glomerular filtration rate (eGFR) $<60 \mathrm{~mL} / \mathrm{min} / 1.73 \mathrm{~m}^{2}$ was considered as renal insufficiency. The term 'smoking' was used for subjects with current smoking habits or subjects who quitted less than one month ago. The diameters of the intravascular stents were grouped if they were $\geq 2.5 \mathrm{~mm}$. The term elderly is used to define subjects of age above 70 years.

\section{Bias}

This study made some efforts to eliminate potential sources of bias. First, it strictly enrolled consecutive patients according to the inclusion and exclusion criteria; Second, laboratory technicians and data analysts were blinded to the original source of samples and patient information; Third, factors that may affect PMI were included in the multivariate analysis.

\section{Statistical analysis}

The statistical analysis was performed using the SPSS 22.0 statistical package. Non-parametric Mann-Whitney U test was used to test the variables. The normal distribution of laboratory assessments was confirmed by KolmogorovSmirnov test. The missing values of continuous variables 
were replaced by the mean and the missing values of ordinal categorical variables were replaced by the median. In retrospective cohort study, inflammatory biomarkers including NLR, CRP, and WBC were allocated with normal transformation by Blom method and renamed as NNLR, NCRP, and NWBC. k-means clustering using NNLR, NCRP and NWBC were performed using SPSS software to create a virtual variable "Inflammatory Trend". Based upon the results of $\mathrm{k}$-means clustering patients were divided into two groups, cluster I (final gathering center, NNLR -0.4873, NWBC -0.5752, NCRP -0.4918) $(\mathrm{n}=3,800)$ and cluster II (final gathering center, NNLR 0.5081, NWBC 0.5999, NCRP 0.5186) ( $\mathrm{n}=3,613)$. Univariate analysis and multivariate regression analysis of each factor were performed by logistic binary regression analysis. In the prospective cohort study, the difference in the incidence of PMI among each group and the relative risk value were calculated by the chi-square test. Factors associated with PMI were identified by univariate logistic regression. Through the univariate analysis, variables with $\mathrm{P}$ value $<0.05$ were screened out for the test of multiple analyses. Multivariate logistic and linear regressions were performed to identify the relationship between the increase of inflammation biomarkers and PMI. Multivariate logistic regression and chi-square test were also performed in subgroup analysis. $\mathrm{P}$ values $<0.05$ (two-tailed) were considered statistically significant.

\section{Sensitivity analysis}

This study investigated the predictability of inflammatory factors on PMI before and after the processing of missing values. For another definition of $\mathrm{PMI}(\mathrm{c} T \mathrm{TnI}>3 \times \mathrm{URL}$ along with a normal baseline range 48 hours after the procedure), this study also explored its relationship with inflammatory factors.

\section{Results}

\section{Baseline characteristics}

In the retrospective cohort study, 13,113 patients received stent implantation at the Sir Run Run Shaw Hospital between December 2009 and December 2017. Among these 5720 patients were omitted from this group because of the previously defined exclusion criterion. Additional details are provided in Figure 1. In all, 7,413 patients receiving elective coronary stent implantation for single- vessel lesions were enrolled. The number of participants with missing CRP, NLR, and WBC data were, 177, 142, and 103 , respectively. The mean age of these patients was $66.54 \pm 10.21$ years, $71.0 \%$ were men, $69.0 \%$ had hypertension and $25.6 \%$ had diabetes mellitus. In the prospective cohort study, 3726 consecutive patients received stent implantation. A total of 2,537 patients were excluded as per the exclusion criteria and finally a total of 1,189 patients were included. The number of participants with missing CRP, NLR, and WBC data were, 52, 36, and 25 , respectively. The subject population in prospective study had a mean age of $65.98 \pm 9.90$ years. Among this, $66.3 \%$ were men, $67.8 \%$ had hypertension and $27.5 \%$ had diabetes mellitus. The levels of myonecrotic markers (cTnI) were measured before and at 8-, 16-, 24- and 48-hours' after PCI. The main demographic, procedural characteristics and angiographic features are listed in Tables 1,2. The baseline characteristics of groups divided by WBC, NLR and CRP are shown in Tables S1-S3.

\section{PMI ratios and logistic regression analysis in the retrospective cohort study}

Comparison with the standard values of $\mathrm{WBC}<$ or $\geq 7.3 \times 10^{9} / \mathrm{L}$, $\mathrm{CRP}<$ or $\geq 3.0 \mathrm{mg} / \mathrm{L}, \mathrm{NLR}<$ or $\geq 2.2$ revealed a higher incidence of PMI in patients with elevated WBC $(12.5 \%$ vs. $14.6 \%, \mathrm{P}$ value $=0.016), \mathrm{CRP}(12.3 \%$ vs. $16.0 \%, \mathrm{P}$ value $<0.001)$, and NLR (11.1\% vs. $14.2 \%$, $\mathrm{P}$ value $<0.001$, Figure $2 A)$.

The univariate analysis suggested that age, gender, current smoking, hypertension, renal insufficiency, B2C type stent, balloon pre-dilation, balloon post-dilation, total stent length (every $10 \mathrm{~mm}$ ), CRP, NLR, WBC had predictive value in the incidence of PMI (Table 3).

After correction of the confounding factors screened from the univariate analysis, the multivariable logistic regression analysis revealed that age, gender, renal insufficiency, balloon post-dilation, total stent length (every $10 \mathrm{~mm}$ ), CRP, NLR can serve as independent predictors of PMI. Elevated inflammation biomarker levels except WBC concentration have a connection with an increased incidence risk of PMI (Table 3).

In subgroup analysis, predictive values of CRP on PMI was consistent across the patients with age $<70$ years (OR 1.069, $95 \%$ CI, 1.017-1.124, $\mathrm{P}$ value $=0.009)$, no hypertension (OR 1.077, 95 \% CI, 1.005-1.154, P value $=0.036)$, male $(\mathrm{OR} 1.062,95 \% \mathrm{CI}, 1.018-1.107$, P value $=0.005)$, no renal insufficiency (OR 1.045, $95 \%$ CI, $1.005-1.088, \mathrm{P}$ value $=0.027)$, smoking $(\mathrm{OR} 1.083,95 \%$ 
Table 1 Baseline characteristics of the sample

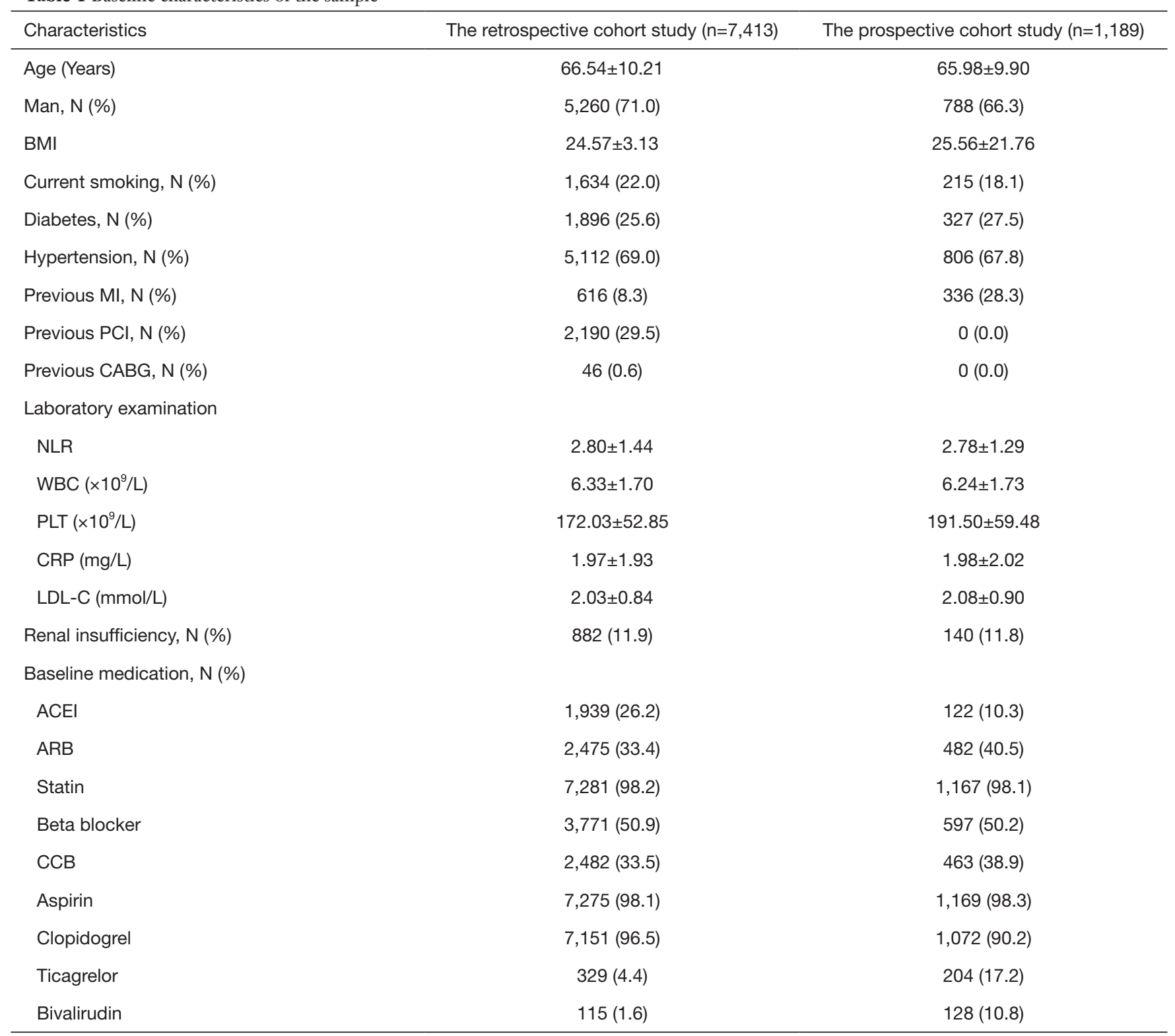

Values are expressed as mean \pm SD or $n(\%)$ unless otherwise indicated. NLR, neutrophil to lymphocyte ratio; WBC, white blood cell; PLT, platelet; CRP, C-creative protein; BMI, Body Mass Index; LDL-C, low-density lipoprotein cholesterol; CABG, Coronary Artery Bypass Grafting; MI, myocardial infarction; PCI, percutaneous coronary intervention; ACEI, Angiotensin-Converting Enzyme Inhibitors; ARB, angiotensin receptor blocker; CCB, calcium channel blocker.

CI, 1.007-1.166, P value $=0.033$, Figure $2 B)$. For NLR, the predictive values in each subgroups, such as patients with age $<70$ years (OR 1.088, 95\% CI, 1.014-1.167, P value $=0.019$ ), hypertension (OR 1.055, 95\% CI, 1.001-1.113, $\mathrm{P}$ value $=0.047)$, no renal insufficiency $(\mathrm{OR} 1.059,95 \%$ CI, $1.002-1.118$, P value $=0.041$, Figure $2 C$ ). Data for each group is shown in Figure 2.

\section{K-means clustering}

In term of patients' demographics, the inflammation biomarkers such as NLR, CRP, WBC and platelet count of cluster II (NLR 3.49, WBC 7.30×10\%/L, CRP $2.81 \mathrm{mg} / \mathrm{L}$ ) were significantly higher than cluster I (NLR 2.14, WBC $5.41 \times 10^{9} / \mathrm{L}, \mathrm{CRP} 1.17 \mathrm{mg} / \mathrm{L}, \mathrm{P}$ value $\left.<0.001\right)$. The proportion of male patients in cluster II with smoking, 
Table 2 Baseline characteristics of distribution of lesion vessels in patients

\begin{tabular}{lcc}
\hline & The retrospective cohort study $(\mathrm{n}=7,413)$ & The prospective cohort study $(\mathrm{n}=1,189)$ \\
\hline LM, N (\%) & $432(5.8)$ & $67(5.6)$ \\
LAD, N (\%) & $3,969(53.5)$ & $642(54.0)$ \\
LCX, N (\%) & $1,220(16.5)$ & $191(16.1)$ \\
RCA, N (\%) & $2,133(28.8)$ & $342(28.8)$ \\
AHA/ACC type B2/C, N (\%) & $2,180(29.4)$ & $747(62.8)$ \\
Coronary calcification, N (\%) & $816(11.0)$ & $121(10.8)$ \\
CTO, N (\%) & $0(0.0)$ & $0(0.0)$ \\
FFR/IVUS/OCT, N (\%) & $679(9.2)$ & $233(19.6)$ \\
Stents number $\geq 2, N(\%)$ & $2,666(36.0)$ & $187(15.7)$ \\
Total stent length (mm) & $33.66 \pm 21.28$ & $39.14 \pm 21.84$ \\
Stent diameter $\geq 2.5 \mathrm{~mm}, \mathrm{~N}(\%)$ & $6,630(89.4)$ & $1,102(92.7)$ \\
Ballon pre-dilation, N (\%) & $6,350(85.7)$ & $1,081(90.9)$ \\
Ballon post-dilation, N (\%) & $6,767(91.3)$ & $1,168(98.2)$ \\
\hline
\end{tabular}

Values are expressed as mean \pm SD or $n(\%)$ unless otherwise indicated. LM, left main; LAD, left anterior descending branch; LCX, left circumflex artery; RCA, right coronary artery; AHA/ACC, American College of Cardiology/American Heart Association; CTO, chronic total occlusion; FFR, fractional flow reserve; IVUS, intravascular ultrasound; OCT, optical coherent tomography.

hypertension, diabetes, and renal insufficiency was higher. Patients in cluster II were older, had higher BMI, higher low-density lipoprotein and higher platelet count, Table S4.

Higher rate of PMI was found in patients of cluster II $(11.3 \%$ vs. $14.8 \%$, P value $<0.001$, Figure $2 A)$. After correction of confounding factors screened from univariate analysis, the virtual variable inflammatory trend had a predictive value for PMI (OR 1.202, 95\% CI, 1.042-1.387, $\mathrm{P}$ value $=0.012$, Table S5). In the subgroup analysis, the virtual variable inflammatory trend served as an independent predictor of PMI in female patients (OR 1.315, 95\% CI, 1.026-1.685, P value $=0.031)$, hypertension $(\mathrm{OR}$ $1.217,95 \%$ CI, $1.030-1.438, \mathrm{P}$ value $=0.021$ ), no current smoking (OR 1.234, $95 \%$ CI, 1.051-1.499, $\mathrm{P}$ value $=0.010$ ), no renal insufficiency (OR 1.192, 95 \% CI, 1.020-1.392, P value $=0.027$, Figure $S 1$ ).

\section{PMI ratios and Chi-square test in the prospective cohort study}

The prospective cohort study employed the same cut-off points for inflammatory markers as the retrospective study. There are higher incidence of PMI in patients with elevated CRP $(13.9 \%$ vs. $19.7 \%, \mathrm{P}$ value $=0.025)$ and $\operatorname{NLR}(12.4 \%$ vs. $16.8 \%, \mathrm{P}$ value $=0.041$ ), but in patients with elevated WBC $(14.7 \%$ vs. $16.6 \%$, P value $=0.416)$, this study did not observe significant differences (Figure $3 A$ ).

The RR of patients with elevated CRP was 1.412 (95\% CI, 1.049-1.190, P value $=0.025$, Figure $3 B$ ). The RR of patients with $\mathrm{WBC}$ concentration $>7.30 \times 10^{9} / \mathrm{L}$ was 1.134 $(95 \%$ CI, 0.839-1.531, P value $=0.416$, Figure 3C). The relative risk (RR) of patients with elevated NLR was 1.354 $(95 \%$ CI, $1.009-1.818, \mathrm{P}$ value $=0.041$, Figure 3D).

In the subgroup analysis of NLR, the RR value was statistically significant in subjects of age $<70$ years (RR 1.503 , 95\% CI, 1.005-2.247, P value $=0.044)$, hypertension $(\mathrm{RR}$ $1.612,95 \%$ CI, 1.121-2.318, P value $=0.008$, Figure $3 D)$. The relationship between CRP and PMI was consistent across above mentioned subgroups of patients such as population of hypertension (RR 1.411, $95 \%$ CI, $1.005-$ $1.981, \mathrm{P}$ value $=0.0496)$, female $(\mathrm{RR} 1.875,95 \% \mathrm{CI}, 1.205$ 2.916 , $\mathrm{P}$ value $=0.006)$, no current smoking $(\mathrm{RR} 1.442,95 \%$ CI, 1.048-1.984, $\mathrm{P}$ value $=0.027$ ), no renal insufficiency $(\mathrm{RR}$ $1.431,95 \%$ CI, 1.018-2.012, P value $=0.042$ ), Figure $3 B$.

Overall, in the retrospective cohort study, CRP and NLR were found as independent risk factors for PMI. We also found that $\mathrm{WBC}$ cannot be considered as a risk factor. The subgroup analysis revealed that CRP was the most 
A

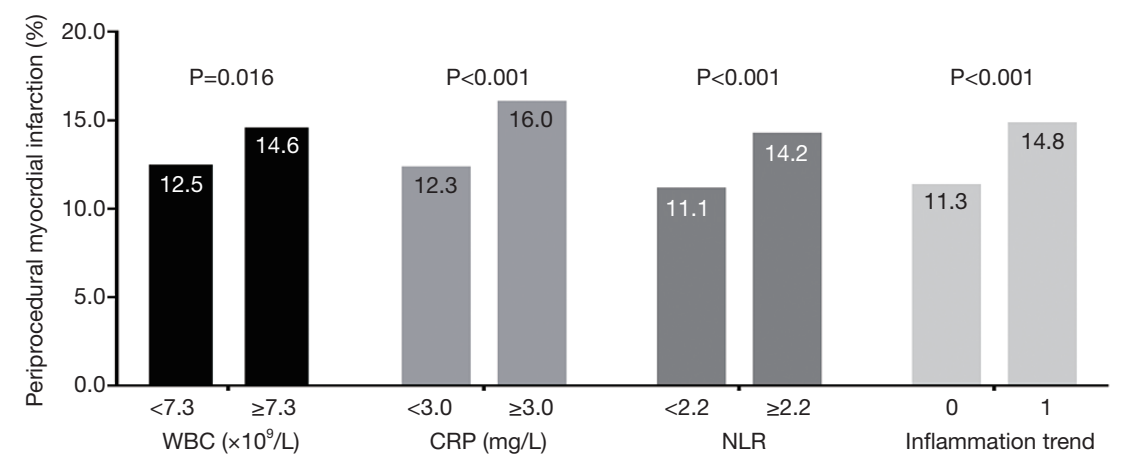

B
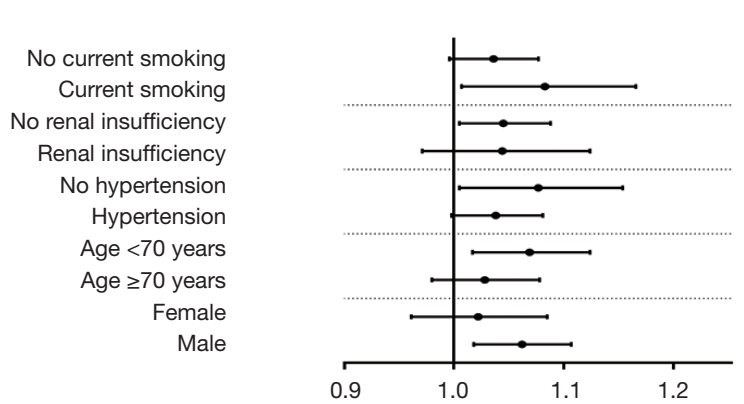

Adjusted OR (95\%Cl)

1.036 (0.996-1.077)

1.083 (1.007-1.166)

1.045 (1.005-1.088)

1.044 (0.971-1.124)

1.077 (1.005-1.154)

1.038 (0.998-1.081)

1.069 (1.017-1.124)

$1.028(0.980-1.078)$

$1.022(0.961-1.085)$

1.062 (1.018-1.107)

$P$ value

0.080

$0.033^{*}$

$0.027^{*}$

0.245

$0.036^{*}$

0.065

$0.009^{*}$

0.254

0.492

$0.005^{\star}$

C

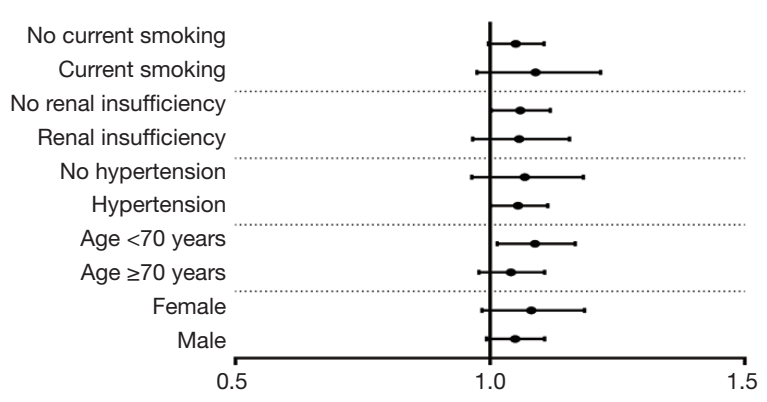

$\begin{array}{cc}\text { Adjusted OR }(95 \% \mathrm{Cl}) & \text { Pvalue } \\ 1.050(0.997-1.106) & 0.065 \\ 1.089(0.974-1.217) & 0.133 \\ 1.059(1.002-1.118) & 0.041^{*} \\ 1.057(0.966-1.156) & 0.227 \\ 1.068(0.964-1.183) & 0.211 \\ 1.055(1.001-1.113) & 0.047^{\star} \\ 1.088(1.014-1.167) & 0.019^{\star} \\ 1.041(0.978-1.107) & 0.206 \\ 1.080(0.984-1.185) & 0.106 \\ 1.049(0.993-1.107) & 0.086\end{array}$

Figure 2 PMI ratios and logistic regression analysis in retrospective cohort study. (A) Difference in the incidence of PMI between groups divided according to WBC, NLR, CRP and Inflammatory trend ( $\mathrm{n}=7,413)$. (B) The relationship between CRP and PMI was analysed by multivariable logistic regression analysis in predefined subgroups. (C) The relationship between NLR and PMI was analysed by multivariable logistic regression analysis in predefined subgroups. * $\mathrm{P}<0.05$. PMI, periprocedural myocardial infarction; CRP, C-reactive protein; WBC, white blood cell; NLR, neutrophil to lymphocyte ratio.

stable predictor. The virtual variable inflammatory trend had predictive values for PMI particularly in the female population, or patients with hypertension, no current smoking, and no renal insufficiency. It was observed that, in a prospective cohort study, the increase of CRP and NLR can elevate the incidence of PMI, while WBC has no effect.

\section{Sensitivity analysis}

In the analysis, prior to the replacement of the missing value, the retrospective study showed that CRP (OR 1.045, $95 \%$ CI, 1.009-1.083, P value $=0.013)$, and NLR $($ OR 1.054, $95 \% \mathrm{CI}, 1.005-1.105$, $\mathrm{P}$ value $=0.031)$ were risk factors for PMI, while WBC (OR 1.015, 95 \% CI, 0.972-1.060, P value $=0.498)$ was not; In the prospective studies, the PMI incidence was higher in patients with elevated CRP $(13.9 \%$ vs. $19.7 \%, \mathrm{P}$ value $=0.025)$ and NLR $(12.4 \%$ vs. $16.8 \%, \mathrm{P}$ value $=0.041$, while $\mathrm{WBC}$ had no effect on the incidence of PMI. 2. For another definition of PMI $(\mathrm{cTnI}>3 \times \mathrm{URL}$ along with a normal baseline range 48 hours after the 
A

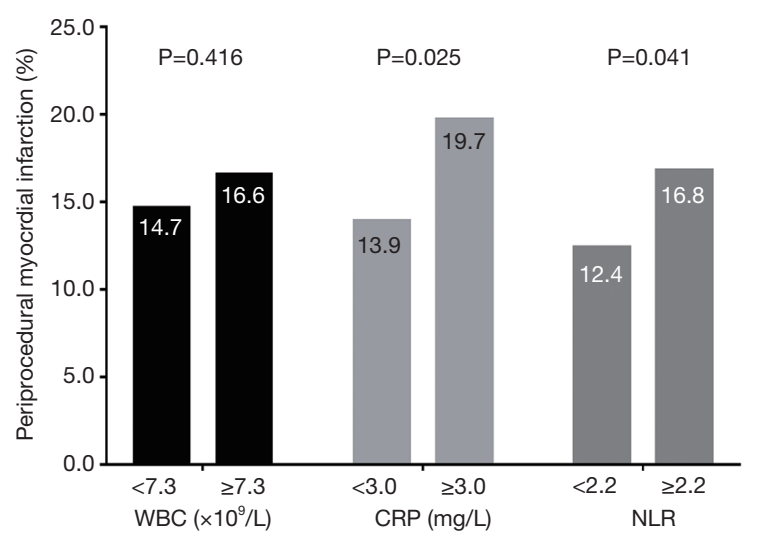

B

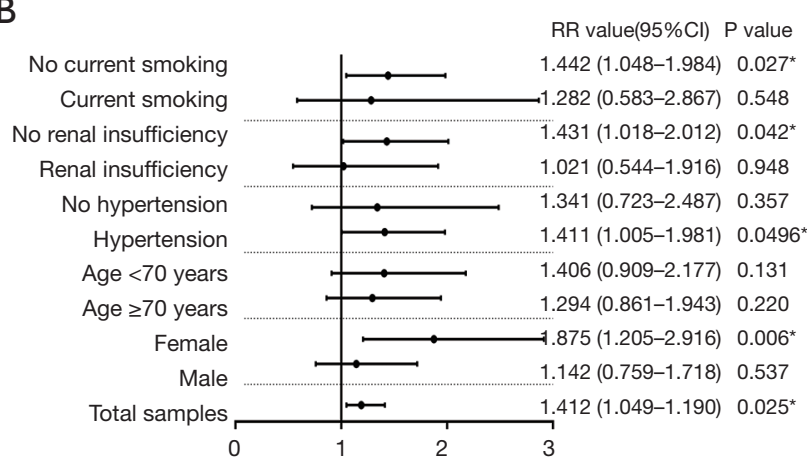

C
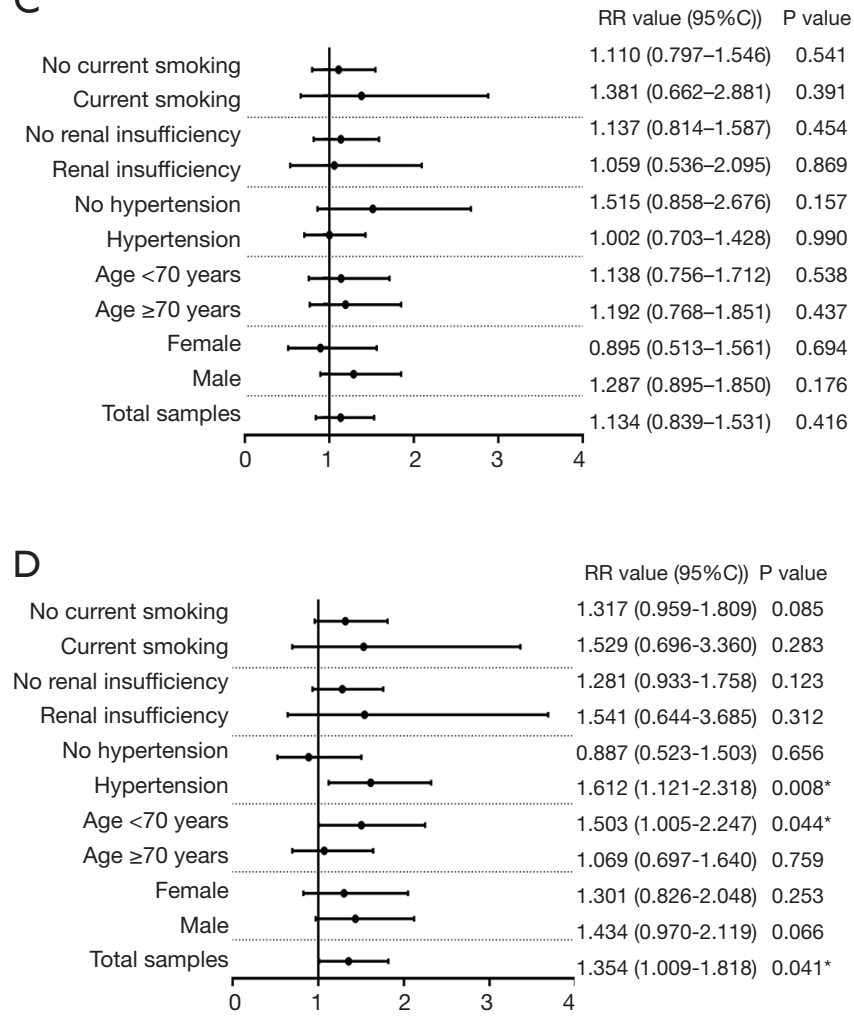

Figure 3 PMI ratios and Chi-square test in prospective cohort study. (A) Difference in the incidence of PMI between groups divided according to WBC, NLR and CRP (n=1,189). (B) The relationship between CRP and PMI was analysed by Chi-square test in the sample and predefined subgroups. (C) The relationship between WBC and PMI was analysed by Chi-square test in the sample and predefined subgroups. (D) The relationship between NLR and PMI was analysed by Chi-square test in the sample and predefined subgroups. *, $\mathrm{P}<0.05$. PMI, periprocedural myocardial infarction; CRP, C-reactive protein; WBC, white blood cell; NLR, neutrophil to lymphocyte ratio; RR, relative risk.

procedure), the retrospective study showed that CRP (OR $1.043,95 \%$ CI, $1.012-1.074$, P value $=0.006)$, and NLR $(\mathrm{OR} 1.058,95 \% \mathrm{CI}, 1.016-1.103$, $\mathrm{P}$ value $=0.007)$ were risk factors for PMI, while WBC (OR 0.989, 95\% CI, 0.954$1.026, \mathrm{P}$ value $=0.560$ ) was not; In the prospective studies, the PMI incidence was higher in patients with elevated CRP $(21.0 \%$ vs. $26.1 \%$, P value $=0.042)$ and NLR $(18.5 \%$ vs. $24.1 \%, \mathrm{P}$ value $=0.022)$, and $\mathrm{WBC}(21.7 \%$ vs. $23.1 \%, \mathrm{P}$ value $=0.416$ ) had no effect on the incidence of PMI.

\section{Discussion}

Over the past few years, clinical researchers across the world have shown great interest in the prevention of perioperative complications. Magnetic resonance imaging (MRI) have demonstrated that most patients have myocardial injury during the perioperative period of PCI (27). Therefore, it is important to identify predictors of PMI during PCI. Inflammation is a recognized risk factor for CAD (28). It is considered as a leading mechanism for the course of development of atherosclerosis. Inflammatory biomarkers such as CRP and NLR are closely related to PMI incidence and enhanced risk stratification $(15,18,20)$. However, their utility as a biomarker is still controversial. Some studies have reported that the increase in NLR is connected to the elevated risk of PMI in patients undergoing non-urgent PCI especially for values $\geq 3$ (15). A study by Bressi et al. have demonstrated that there was no relationship between preprocedural NLR values and the incidence of PMI during the elective percutaneous coronary intervention (17). Also, the findings of the studies focused on exploring a relationship between cardiac troponin and CRP are 
Table 3 Logistics regression of inflammation biomarkers

\begin{tabular}{|c|c|c|c|c|c|c|c|c|}
\hline \multirow{2}{*}{$\begin{array}{l}\text { Variable } \\
\text { WBC }\end{array}$} & \multicolumn{4}{|c|}{ Simple regression } & \multicolumn{4}{|c|}{ Multiple regression } \\
\hline & $\frac{\mathrm{OR}}{1.046}$ & 1.006 & 1.087 & $\begin{array}{c}P \\
0.025\end{array}$ & $\frac{\mathrm{OR}}{1.013}$ & 0.971 & 1.057 & $\frac{P}{0.548}$ \\
\hline CRP & 1.079 & 1.045 & 1.114 & $<0.001$ & 1.046 & 1.011 & 1.083 & $0.010^{*}$ \\
\hline NLR & 1.106 & 1.062 & 1.153 & $<0.001$ & 1.056 & 1.007 & 1.107 & $0.024^{*}$ \\
\hline Man & 0.740 & 0.641 & 0.854 & $<0.001$ & 0.732 & 0.624 & 0.859 & $<0.001^{*}$ \\
\hline BMI & 0.979 & 0.957 & 1.000 & 0.054 & & & & \\
\hline Current smoking & 0.881 & 0.683 & 0.962 & 0.016 & 0.970 & 0.803 & 1.173 & 0.755 \\
\hline Diabetes & 1.157 & 0.995 & 1.346 & 0.059 & & & & \\
\hline Renal insufficiency & 1.766 & 1.472 & 2.118 & $<0.001$ & 1.266 & 1.034 & 1.551 & $0.023^{*}$ \\
\hline CCB & 1.097 & 0.952 & 1.264 & 0.199 & & & & \\
\hline AHA/ACC Type B2/C & 1.346 & 1.166 & 1.552 & $<0.001$ & 1.143 & 0.982 & 1.330 & 0.084 \\
\hline Balloon pre-dilation & 1.334 & 1.082 & 1.645 & 0.007 & 1.147 & 0.992 & 1.427 & 0.220 \\
\hline Balloon post-dilation & 1.784 & 1.332 & 2.388 & $<0.001$ & 1.425 & 1.052 & 1.929 & $0.022^{*}$ \\
\hline Total stent length (Every $10 \mathrm{~mm}$ ) & 1.325 & 1.288 & 1.363 & $<0.001$ & 1.312 & 1.274 & 1.351 & $<0.001^{*}$ \\
\hline Stent size $>2.5 \mathrm{~mm}$ & 1.067 & 0.852 & 1.335 & 0.141 & & & & \\
\hline
\end{tabular}

Values are expressed as mean $\pm \mathrm{SD}$ or $\mathrm{n}(\%)$ unless otherwise indicated. *, $\mathrm{P}<0.05$. OR odds ratio. Dichotomized values with statistical significance are described in the table. WBC, white blood cell; CRP, C-creative protein; NLR, neutrophil to lymphocyte ratio; BMI, Body Mass Index; LDL-C, low-density lipoprotein cholesterol; AHA/ACC, American College of Cardiology/American Heart Association.

contradictory. Four out of the six studies suggest a positive correlation between CRP and PMI while the other two suggest no relationship $(8,10,11,14)$. Preoperative WBC is independently associated with higher perioperative cardiac enzyme release and mortality after PCI (19). Another study suggests that WBC is not independently associated with PMI (16). The current study is aimed at exploring the connection between the increase of inflammatory biomarkers and the incidence of PMI in patients with elective PCI both in retrospective and prospective manner.

The present study provided evidence that elevated inflammation biomarkers, NLR and CRP, were independent factors on PMI especially after adjusting factors related to the lesions and procedural characteristics. WBC and CRP are well-known inflammation markers and key factors in the process of hemostasis and thrombosis. An elevated level of total WBC count, in a previous study on patients with acute MI, was considered to have a connection with increased poor prognosis and mortality (29). Also, pre-procedural CRP or WBC levels were found to be associated with PMI $(18,19,30)$. In this study, WBC level seems to have no effect on the occurrence of PMI, which is consistent with the findings (16) of Verdoia et al., suggesting that low-level increase of myocardial enzymes might have a correlation with WBC but not the high level. Recently NLR is being considered as a new type of inflammation sensitive marker. Few studies have reported that it could serve as an indicator for predicting clinical prognosis of patients who suffer from stable CAD $(9,13)$. In patients undergoing elective PCI Elevated NLR level increases the risk of PMI in patients undergoing elective coronary intervention (15). The theory that three scenarios promote thrombosis, proposed by Virchow, believes that inflammation plays a crucial role in thrombus formation $(31,32)$. In the human circulatory system, the presence of inflammatory reactions can increase levels of clotting factors such as fibrinogen. Platelets play 
a momentous role in the process causing instability to the atherosclerotic plaques after enhanced responsiveness, which is mediated by reactive oxygen species, cytokines and other mediators (33) is strictly linked with the enhanced pro-thrombotic status (28). Both retrospective and prospective cohort studies suggest that the predictive value of CRP is better than NLR. However, after combining the results of mutual verification between the two studies, when comparing CRP with NLR, no obvious pros and cons in the stability of predicting PMI were found.

It is worth mentioning that renal insufficiency and total stent length were also found as risk factors for PMI in this study. Renal insufficiency, as previously reported, has characteristics disturbances due to high perfusion and reduced coronary blood flow due to microvascular abnormalities (34). In addition to the sudden decrease in partially activated prothrombin and thrombin time caused by hemodialysis, it also increases the risk of massive thromboembolism and hypercoagulation (35). The findings related to the influence of total stent length in this study corroborate with previous reports (36). The fact that whether this association includes confounding factors of plaque lesions, or directly reflects the larger vascular damage due to long stent length requires further exploration. For balloon post-dilation, although the exact mechanism or its association with PMI is unclear, plasma b-type natriuretic peptide levels were significantly elevated post-dilation. In addition, increased levels of troponin I and high sensitive CRP post-dilation suggests the possibility of more $M I$ and inflammation (37). Further research is required on these aspects as well.

The present study differs from earlier reports in different ways. First, for a single-center study, the sample size is considerable. Also, complementary information can be obtained from both prospective and retrospective findings. As the subjects with multi-vessel PCI were excluded the influence of pathological features and interventional operations for other vessels were minimized leading to accurate conclusions. We also did not include PMI subjects due to mechanical damage such as aortic dissection and branch occlusion, this can further help to precisely identify the effect of the inflammation biomarkers on PMI. Subgroup analysis was conducted to further explore specific populations.

Using only one or two biomarkers to reflect inflammation is highly susceptible to interference by other factors therefore, we have integrated different inflammatory indicators into a unified system to reflect overall inflammatory status through $\mathrm{k}$-means clustering. Interestingly there was a relationship between the virtual variable inflammatory trend and the incidence of PMI, indicating that it is feasible to use a unified model to combine inflammation-related indicators in order to predict the incidence of PMI accurately.

This study includes retrospective and prospective research, and the two parts of the study are consistent with category boundaries of variables. Besides, the endpoint event indicators of this study were collected in the hospital within 48 hours after PCI, the follow-up rates were very high, negating attrition bias. The inclusion and exclusion criteria of this study were strictly enforced, thereby increasing the chance of reflecting the status of single CAD patients. These factors strengthen the study's external validity.

First, as a single-center study, residual confounding or selection bias cannot be completely ruled out. Second, as mentioned the disturbances due to mechanical damages such as aortic dissection and branch occlusion were ignored in order to precisely measure the influence of inflammatory markers. Even though chest pain was recorded in many cases the electrocardiogram changes could not be collected as the paper ECG ink disappeared over a long period of time. This further makes the PMI defined in this study not completely consistent with the fourth definition of myocardial infarction which includes additional non-cardiac markers. Third, plaque characteristics could also influence the occurrence of PMI. In this study, we can only define the characteristics of the lesion by angiography results due to the unavailability of FFR/IVUS/OCT in most patients.

\section{Conclusions}

In patients with elective PCI for single-vessel lesions, a higher CRP increases the risk of PMI, particularly in patients of no current smoking or renal insufficiency. The increase of NLR was an independent risk factor for PMI, especially for patients under the age of 70 and hypertension. WBC level seems to have no impact on the occurrence of PMI.

\section{Acknowledgments}

Funding: This work was supported by the Natural Science Foundation of Zhejiang Province (LY18H020007 and LQ17H020002), China. 


\section{Footnote}

Reporting Checklist: The authors have completed the STROBE reporting checklist. Available at http://dx.doi. org/10.21037/jtd-20-1605

Data Sharing Statement: Available at http://dx.doi. org/10.21037/jtd-20-1605

Conflicts of Interest: All authors have completed the ICMJE uniform disclosure form (available at http://dx.doi. org/10.21037/jtd-20-1605). The authors have no conflicts of interest to declare.

Ethical Statement: The authors are accountable for all aspects of the work in ensuring that questions related to the accuracy or integrity of any part of the work are appropriately investigated and resolved. The study was conducted in accordance with the Declaration of Helsinki (as revised in 2013). The retrospective study was approved by the Ethics Committee of Sir Run Run Shaw Hospital of Zhejiang University (NO.20200224-33), The prospective study was registered at the Chinese Clinical Trial Registry(chiCTR-RPC-17014094), and informed consent was obtained from all patients. This study did not include subjects under 18 years of age or those with limited capacity for civil conduct.

Open Access Statement: This is an Open Access article distributed in accordance with the Creative Commons Attribution-NonCommercial-NoDerivs 4.0 International License (CC BY-NC-ND 4.0), which permits the noncommercial replication and distribution of the article with the strict proviso that no changes or edits are made and the original work is properly cited (including links to both the formal publication through the relevant DOI and the license). See: https://creativecommons.org/licenses/by-nc-nd/4.0/.

\section{References}

1. Benjamin EJ, Blaha MJ, Chiuve SE, et al. Heart Disease and Stroke Statistics-2017 Update: A Report From the American Heart Association. Circulation 2017;135:e146-603.

2. Levine GN, Bates ER, Blankenship JC, et al. 2011 ACCF/AHA/SCAI Guideline for Percutaneous Coronary Intervention: executive summary: a report of the American College of Cardiology Foundation/American Heart
Association Task Force on Practice Guidelines and the Society for Cardiovascular Angiography and Interventions. Circulation 2011;124:2574-609.

3. Feldman DN, Kim L, Rene AG, et al. Prognostic value of cardiac troponin-I or troponin-T elevation following nonemergent percutaneous coronary intervention: a meta-analysis. Catheter Cardiovasc Interv 2011;77:1020-30.

4. Prasad A, Herrmann J. Myocardial infarction due to percutaneous coronary intervention. $\mathrm{N}$ Engl J Med 2011;364:453-64.

5. Park DW, Kim YH, Yun SC, et al. Frequency, causes, predictors, and clinical significance of peri-procedural myocardial infarction following percutaneous coronary intervention. Eur Heart J 2013;34:1662-9.

6. Park DW, Yun SC, Lee JY, et al. C-reactive protein and the risk of stent thrombosis and cardiovascular events after drug-eluting stent implantation. Circulation 2009;120:1987-95.

7. Choi DH, Park KW, Yang HM, et al. Renal dysfunction and high levels of hsCRP are additively associated with hard endpoints after percutaneous coronary intervention with drug eluting stents. Int J Cardiol 2011;149:174-81.

8. Yao M, Zhao L, Wu L, et al. Predictive value of baseline C-reactive protein for periprocedural myocardial infraction of higher risk stratifications: A retrospective cohort clinical study. Anatol J Cardiol 2018;20:310-7.

9. Fowler AJ, Agha RA. Neutrophil/lymphocyte ratio is related to the severity of coronary artery disease and clinical outcome in patients undergoing angiography-the growing versatility of NLR. Atherosclerosis 2013;228:44-5.

10. Hubacek J, Basran RS, Shrive FM, et al. Prognostic implications of $\mathrm{C}$-reactive protein and troponin following percutaneous coronary intervention. Can J Cardiol 2009;25:e42-7.

11. Saleh N, Svane B, Velander M, et al. C-reactive protein and myocardial infarction during percutaneous coronary intervention. J Intern Med 2004;255:33-9.

12. Shah N, Parikh V, Patel N, et al. Neutrophil lymphocyte ratio significantly improves the Framingham risk score in prediction of coronary heart disease mortality: insights from the National Health and Nutrition Examination Survey-III. Int J Cardiol 2014;171:390-7.

13. Park BJ, Shim JY, Lee HR, et al. Relationship of neutrophil-lymphocyte ratio with arterial stiffness and coronary calcium score. Clin Chim Acta 2011;412:925-9.

14. Gach O, Louis O, Chapelle JP, et al. Baseline inflammation 
is not predictive of periprocedural troponin elevation after elective percutaneous coronary intervention. Heart Vessels 2009;24:267-70.

15. Verdoia M, Schaffer A, Barbieri L, et al. Impact of neutrophil-to-lymphocyte ratio on periprocedural myocardial infarction in patients undergoing non-urgent percutaneous coronary revascularisation. Neth Heart J 2016;24:462-74.

16. Verdoia M, Schaffer A, Barbieri L, et al. Uric acid and risk of periprocedural myocardial infarction in patients undergoing percutaneous coronary intervention. Diabetes Metab Res Rev 2014;30:297-304.

17. Bressi E, Mangiacapra F, Ricottini E, et al. Relation of Neutrophil to Lymphocyte Ratio With Periprocedural Myocardial Damage in Patients Undergoing Elective Percutaneous Coronary Intervention. Am J Cardiol 2016;118:980-4.

18. Jeong YH, Tantry US, Min JH, et al. Influence of platelet reactivity and inflammation on peri-procedural myonecrosis in East Asian patients undergoing elective percutaneous coronary intervention. Int J Cardiol 2013;168:427-35.

19. Gurm HS, Bhatt DL, Gupta R, et al. Preprocedural white blood cell count and death after percutaneous coronary intervention. Am Heart J 2003;146:692-8.

20. Niccoli G, Sgueglia GA, Latib A, et al. Association of baseline C-reactive protein levels with periprocedural myocardial injury in patients undergoing percutaneous bifurcation intervention: a CACTUS study subanalysis. Catheter Cardiovasc Interv 2014;83:E37-44.

21. Novack V, Pencina M, Cohen DJ, et al. Troponin criteria for myocardial infarction after percutaneous coronary intervention. Arch Intern Med 2012;172:502-8.

22. Vranckx P, Farooq V, Garg S, et al. Different cardiac biomarkers to detect peri-procedural myocardial infarction in contemporary coronary stent trials: impact on outcome reporting. Heart 2012;98:1424-30.

23. Thygesen K, Alpert JS, Jaffe AS, et al. Fourth Universal Definition of Myocardial Infarction (2018). J Am Coll Cardiol 2018;72:2231-64.

24. Alpert JS, Thygesen K, Antman E, et al. Myocardial infarction redefined--a consensus document of The Joint European Society of Cardiology/American College of Cardiology Committee for the redefinition of myocardial infarction. J Am Coll Cardiol 2000;36:959-69.

25. Thygesen K, Alpert JS, Jaffe AS, et al. Third universal definition of myocardial infarction. J Am Coll Cardiol
2012;60:1581-98.

26. Moussa ID, Klein LW, Shah B, et al. Consideration of a new definition of clinically relevant myocardial infarction after coronary revascularization: an expert consensus document from the Society for Cardiovascular Angiography and Interventions (SCAI). J Am Coll Cardiol 2013;62:1563-70.

27. Selvanayagam JB, Porto I, Channon K, et al. Troponin elevation after percutaneous coronary intervention directly represents the extent of irreversible myocardial injury: insights from cardiovascular magnetic resonance imaging. Circulation 2005;111:1027-32.

28. Mach F, Schonbeck U, Bonnefoy JY, et al. Activation of monocyte/macrophage functions related to acute atheroma complication by ligation of CD40: induction of collagenase, stromelysin, and tissue factor. Circulation 1997;96:396-9.

29. Prasad A, Stone GW, Stuckey TD, et al. Relation between leucocyte count, myonecrosis, myocardial perfusion, and outcomes following primary angioplasty. Am J Cardiol 2007;99:1067-71.

30. Lansky AJ, Stone GW. Periprocedural myocardial infarction: prevalence, prognosis, and prevention. Circ Cardiovasc Interv 2010;3:602-10.

31. Lippi G, Franchini M, Targher G. Arterial thrombus formation in cardiovascular disease. Nat Rev Cardiol 2011;8:502-12.

32. Lip GY, Blann AD. Thrombogenesis and fibrinolysis in acute coronary syndromes. Important facets of a prothrombotic or hypercoagulable state? J Am Coll Cardiol 2000;36:2044-6.

33. Becatti M, Fiorillo C, Gori AM, et al. Platelet and leukocyte ROS production and lipoperoxidation are associated with high platelet reactivity in Non-ST elevation myocardial infarction (NSTEMI) patients on dual antiplatelet treatment. Atherosclerosis 2013;231:392-400.

34. Sobkowicz B, Tomaszuk-Kazberuk A, Kralisz P, et al. Coronary blood flow in patients with end-stage renal disease assessed by thrombolysis in myocardial infarction frame count method. Nephrol Dial Transplant 2010;25:926-30.

35. Surovikina MS, Samoilenko VV, Vlasova EA, et al. Changes in plasmic and platelet hemostasis in patients with chronic renal failure in hemodialysis. Urologiia 2012;(1):25-9.

36. Caputo RP, Goel A, Pencina M, et al. Impact of drug 
eluting stent length on outcomes of percutaneous coronary intervention (from the EVENT registry). Am J Cardiol 2012;110:350-5.

37. Wu GY, Zong GJ, Chen JK, et al. Changes of plasma

Cite this article as: Zhao L, Li Y, Xu T, Luan Y, Lv Q, Wang Y, Lv X, Fu G, Zhang W. Impact of increased inflammation biomarkers on periprocedural myocardial infarction in patients undergoing elective percutaneous coronary intervention: a cohort study. J Thorac Dis 2020;12(10):5398-5410. doi: 10.21037/ jtd-20-1605
B-type natriuretic peptide levels after high-pressure postdilation following coronary stent deployment. PLoS One 2013;8:e82357. 
Table S1 Baseline characteristics according to CRP levels

\begin{tabular}{|c|c|c|c|c|c|c|}
\hline \multirow[b]{2}{*}{ Characteristics } & \multicolumn{3}{|c|}{ The retrospective cohort study } & \multicolumn{3}{|c|}{ The prospective cohort study } \\
\hline & $\begin{array}{c}\mathrm{CRP}<3 \mathrm{mg} / \mathrm{L} \\
\quad(\mathrm{n}=5,896)\end{array}$ & $\begin{array}{c}\mathrm{CRP} \geq 3 \mathrm{mg} / \mathrm{L} \\
(\mathrm{n}=1,517)\end{array}$ & $P$ value & $\begin{array}{c}\text { CRP }<3 \mathrm{mg} / \mathrm{L} \\
(\mathrm{n}=940)\end{array}$ & $\begin{array}{c}\mathrm{CRP} \geq 3 \mathrm{mg} / \mathrm{L} \\
(\mathrm{n}=249)\end{array}$ & $P$ value \\
\hline Age (Years) & $66.23 \pm 10.22$ & $66.77 \pm 10.10$ & $<0.001$ & $65.28 \pm 9.83$ & $68.63 \pm 9.70$ & $<0.001$ \\
\hline Man, N (\%) & $4,223(71.6)$ & $1,037(68.4)$ & 0.012 & $631(67.1)$ & $157(63.1)$ & 0.227 \\
\hline $\mathrm{BMI}$ & $2,4.50 \pm 3.11$ & $24.86 \pm 3.19$ & $<0.001$ & $25.61 \pm 23.91$ & $25.38 \pm 10.13$ & 0.146 \\
\hline Current smoking, $\mathrm{N}(\%)$ & $1,271(21.6)$ & $363(23.9)$ & 0.047 & $167(17.8)$ & 48 (19.3) & 0.582 \\
\hline Diabetes, N (\%) & $1,484(25.2)$ & $412(27.2)$ & 0.113 & $256(27.2)$ & $71(28.5)$ & 0.688 \\
\hline Hypertension, N (\%) & $4,027(68.3)$ & $1,085(71.5)$ & 0.016 & $625(66.5)$ & $181(72.7)$ & 0.063 \\
\hline Previous MI, N (\%) & $509(8.6)$ & $107(7.1)$ & 0.047 & $258(27.4)$ & 78 (31.3) & 0.227 \\
\hline Previous PCI, N (\%) & $1,820(30.9)$ & $370(24.4)$ & $<0.001$ & 0 & 0 & 1.000 \\
\hline Previous CABG, N (\%) & $34(0.6)$ & $12(0.8)$ & 0.343 & 0 & 0 & 1.000 \\
\hline \multicolumn{7}{|l|}{ Laboratory examination } \\
\hline NLR & $2.74 \pm 1.40$ & $3.05 \pm 1.56$ & $<0.001$ & $2.69 \pm 1.23$ & $3.10 \pm 1.47$ & $<0.001$ \\
\hline WBC $\left(\times 10^{9} / \mathrm{L}\right)$ & $6.22 \pm 1.66$ & $6.75 \pm 1.78$ & $<0.001$ & $6.15 \pm 1.69$ & $6.57 \pm 1.86$ & $<0.001$ \\
\hline $\operatorname{PLT}\left(\times 10^{9} / \mathrm{L}\right)$ & $169.86 \pm 52.41$ & $180.45 \pm 53.71$ & $<0.001$ & $189.71 \pm 57.36$ & $198.23 \pm 66.58$ & 0.137 \\
\hline $\mathrm{CRP}(\mathrm{mg} / \mathrm{L})$ & $1.15 \pm 0.72$ & $5.15 \pm 1.86$ & $<0.001$ & $1.10 \pm 0.73$ & $5.28 \pm 1.91$ & $<0.001$ \\
\hline LDL-C (mmol/L) & $1.88 \pm 0.82$ & $2.18 \pm 0.86$ & $<0.001$ & $2.06 \pm 0.89$ & $2.18 \pm 0.92$ & 0.076 \\
\hline Renal insufficiency, N (\%) & $613(10.4)$ & $269(17.7)$ & $<0.001$ & $82(8.7)$ & $58(23.3)$ & $<0.001$ \\
\hline \multicolumn{7}{|l|}{ Baseline medication, N (\%) } \\
\hline ACEI & $1,550(26.3)$ & $389(25.6)$ & 0.610 & $100(10.6)$ & $22(8.8)$ & 0.405 \\
\hline ARB & $1,952(33.1)$ & $523(34.5)$ & 0.313 & $377(40.1)$ & $105(42.2)$ & 0.556 \\
\hline Statin & $5,790(98.2)$ & $1,491(98.3)$ & 0.826 & $924(98.3)$ & $243(97.6)$ & 0.462 \\
\hline Beta blocker & $2,992(50.7)$ & $779(51.4)$ & 0.674 & $477(50.7)$ & $120(48.2)$ & 0.474 \\
\hline CCB & $1,901(32.2)$ & $581(38.3)$ & $<0.001$ & $357(38.0)$ & $106(42.6)$ & 0.187 \\
\hline Aspirin & $5,789(98.2)$ & $1,486(98.0)$ & 0.557 & 924 (98.3) & $245(98.4)$ & 0.917 \\
\hline Clopidogrel & $5,696(96.6)$ & $1,455(95.9)$ & 0.191 & $854(90.9)$ & $218(87.6)$ & 0.120 \\
\hline Ticagrelor & $253(4.3)$ & $76(5.0)$ & 0.225 & $156(16.6)$ & $48(19.3)$ & 0.319 \\
\hline Bivalirudin & $91(1.5)$ & $24(1.6)$ & 0.913 & $86(9.1)$ & $42(16.9)$ & $<0.001$ \\
\hline \multicolumn{7}{|l|}{ Distribution of lesion vessels, N (\%) } \\
\hline LM & $338(5.7)$ & $94(6.2)$ & 0.492 & $53(5.6)$ & $14(5.6)$ & $<0.001$ \\
\hline LAD & $3,194(54.2)$ & $775(51.1)$ & 0.032 & $499(53.1)$ & $143(57.4)$ & 0.992 \\
\hline LCX & $981(16.6)$ & $239(15.8)$ & 0.408 & $156(16.6)$ & $35(14.1)$ & 0.332 \\
\hline $\mathrm{RCA}$ & $1,653(28.0)$ & $480(31.6)$ & 0.006 & $276(29.4)$ & $66(26.5)$ & 0.376 \\
\hline AHA/ACC type B2/C, N (\%) & $1,703(28.9)$ & $477(31.4)$ & 0.051 & $590(62.8)$ & $157(63.1)$ & 0.934 \\
\hline Coronary calcification, N (\%) & $610(10.3)$ & $206(13.6)$ & $<0.001$ & $96(10.2)$ & $25(10.0)$ & 0.936 \\
\hline CTO, N (\%) & $0(0.0)$ & $0(0.0)$ & 1.000 & $0(0.0)$ & $0(0.0)$ & 1.000 \\
\hline FFR/IVUS/OCT, N (\%) & $545(9.2)$ & $134(8.8)$ & 0.621 & $191(20.3)$ & $42(16.9)$ & 0.223 \\
\hline Stents number $\geq 2, N(\%)$ & $2,086(35.4)$ & $580(38.2)$ & 0.039 & $146(15.5)$ & $41(16.5)$ & 0.719 \\
\hline Total stent length (mm) & $36.35 \pm 21.23$ & $37.84 \pm 21.44$ & 0.005 & $38.80 \pm 21.52$ & $40.39 \pm 23.00$ & 0.037 \\
\hline Stent diameter $\geq 2.5 \mathrm{~mm}, \mathrm{~N}(\%)$ & $5,291(89.7)$ & 1,339 (88.3) & 0.096 & $874(93.0)$ & $228(91.6)$ & 0.447 \\
\hline Ballon pre-dilation, N (\%) & $5,026(85.2)$ & $1,324(87.3)$ & 0.044 & $855(91.0)$ & $226(90.8)$ & 0.924 \\
\hline Ballon post-dilation, N (\%) & $5,365(91.0)$ & $1,402(92.4)$ & 0.079 & $927(98.6)$ & $241(96.8)$ & 0.051 \\
\hline
\end{tabular}

Values are expressed as mean \pm SD or $n(\%)$ unless otherwise indicated. NLR, neutrophil to lymphocyte ratio; WBC, white blood cell; PLT, platelet; CRP, C-creative protein; BMI, Body Mass Index; LDL-C, low-density lipoprotein cholesterol; CABG, Coronary Artery Bypass Grafting; MI, myocardial infarction; PCI, percutaneous coronary intervention; ACEI, Angiotensin-Converting Enzyme Inhibitors; ARB, Angiotensin receptor blocker; CCB, Calcium channel blocker; LM, left main; LAD, left anterior descending branch; LCX, left circumflex artery; RCA, right coronary artery; AHA/ACC, American College of Cardiology/American Heart Association; CTO, chronic total occlusion; FFR, Fractional Flow Reserve; IVUS, intravascular ultrasound; OCT, optical coherent tomography. 
Table S2 Baseline characteristics according to NLR levels

\begin{tabular}{|c|c|c|c|c|c|c|}
\hline \multirow{2}{*}{ Characteristics } & \multicolumn{3}{|c|}{ The retrospective cohort study } & \multicolumn{3}{|c|}{ The prospective cohort study } \\
\hline & $N L R<2.2(n=2,817)$ & $N L R \geq 2.2(n=4,596)$ & $P$ value & NLR $<2.2(n=444)$ & $N L R \geq 2.2(n=745)$ & $P$ value \\
\hline Age (Years) & $64.98 \pm 10.14$ & $67.50 \pm 10.14$ & $<0.001$ & $64.39 \pm 9.85$ & $66.92 \pm 9.81$ & $<0.001$ \\
\hline Man, N (\%) & $1847(65.6)$ & $3413(74.3)$ & $<0.001$ & $269(60.6)$ & $519(69.7)$ & 0.001 \\
\hline $\mathrm{BMI}$ & $24.76 \pm 3.04$ & $24.46 \pm 3.17$ & $<0.001$ & $25.84 \pm 21.79$ & $25.40 \pm 21.75$ & 0.059 \\
\hline Current smoking, $\mathrm{N}(\%)$ & $651(23.1)$ & $9,883(21.4)$ & 0.083 & $87(19.6)$ & $128(17.2)$ & 0.296 \\
\hline Diabetes, N (\%) & $682(24.2)$ & $1,214(26.4)$ & 0.035 & $117(26.4)$ & $210(28.2)$ & 0.493 \\
\hline Hypertension, N (\%) & $1,845(65.5)$ & $3,267(71.1)$ & $<0.001$ & $291(65.5)$ & $515(69.1)$ & 0.201 \\
\hline Previous MI, N (\%) & $213(7.6)$ & $403(8.8)$ & 0.068 & $115(25.9)$ & $221(29.7)$ & 0.163 \\
\hline Previous PCI, N (\%) & $803(28.5)$ & $1,387(30.2)$ & 0.125 & 0 & 0 & 1.000 \\
\hline Previous CABG, N (\%) & $17(0.6)$ & $29(0.6)$ & 0.884 & 0 & 0 & 1.000 \\
\hline \multicolumn{7}{|l|}{ Laboratory examination } \\
\hline NLR & $1.70 \pm 0.34$ & $3.47 \pm 1.47$ & $<0.001$ & $1.70 \pm 0.33$ & $3.42 \pm 1.23$ & $<0.001$ \\
\hline WBC $\left(\times 10^{9} / L\right)$ & $5.99 \pm 1.57$ & $6.54 \pm 1.74$ & $<0.001$ & $5.89 \pm 1.61$ & $6.44 \pm 1.77$ & $<0.001$ \\
\hline $\operatorname{PLT}\left(\times 10^{9} / \mathrm{L}\right)$ & $174.37 \pm 51.79$ & $170.59 \pm 53.44$ & $<0.001$ & $191.53 \pm 56.37$ & $191.42 \pm 61.30$ & 0.652 \\
\hline $\mathrm{CRP}(\mathrm{mg} / \mathrm{L})$ & $1.76 \pm 1.72$ & $2.09 \pm 2.04$ & $<0.001$ & $1.78 \pm 1.88$ & $2.09 \pm 2.09$ & 0.010 \\
\hline LDL-C (mmol/L) & $2.12 \pm 0.86$ & $1.97 \pm 0.82$ & $<0.001$ & $2.25 \pm 0.96$ & $1.99 \pm 0.84$ & $<0.001$ \\
\hline Renal insufficiency, N (\%) & $227(8.1)$ & $655(14.3)$ & $<0.001$ & $32(7.2)$ & $108(14.5)$ & $<0.001$ \\
\hline \multicolumn{7}{|l|}{ Baseline medication } \\
\hline ACEI, N (\%) & $692(24.6)$ & $1,247(27.1)$ & 0.015 & $41(9.2)$ & $81(10.9)$ & 0.368 \\
\hline ARB, N (\%) & $888(31.5)$ & $1,587(34.5)$ & 0.008 & $175(39.4)$ & 307 (41.2) & 0.542 \\
\hline Statin, N (\%) & 2,766 (98.2) & $4,515(98.2)$ & 0.879 & $430(96.8)$ & 737 (98.9) & 0.010 \\
\hline Beta blocker, N (\%) & $1,437(51.0)$ & $2,334(50.8)$ & 0.849 & $218(49.1)$ & $379(50.9)$ & 0.554 \\
\hline CCB, N (\%) & $896(31.8)$ & $1,586(34.5)$ & 0.017 & $161(36.3)$ & $302(40.5)$ & 0.144 \\
\hline Aspirin, N (\%) & 2,766 (98.2) & $4,509(98.1)$ & 0.799 & $434(97.7)$ & $735(98.7)$ & 0.238 \\
\hline Clopidogrel, N (\%) & 2,742 (97.3) & 4,409 (95.9) & 0.001 & $413(93.0)$ & $659(88.5)$ & 0.011 \\
\hline Ticagrelor, N (\%) & $95(3.4)$ & $234(5.1)$ & $<0.001$ & $61(13.7)$ & $143(19.2)$ & 0.016 \\
\hline Bivalirudin, N (\%) & $39(1.4)$ & $76(1.7)$ & 0.363 & $45(10.1)$ & $83(11.1)$ & 0.588 \\
\hline \multicolumn{7}{|l|}{ Distribution of lesion vessels } \\
\hline LM, N (\%) & $158(5.6)$ & $274(6.0)$ & 0.529 & $23(5.2)$ & $44(5.9)$ & 0.600 \\
\hline LAD, N (\%) & $1,576(55.9)$ & $2,393(52.1)$ & 0.001 & $248(55.9)$ & $394(52.9)$ & 0.320 \\
\hline LCX, N (\%) & $432(15.3)$ & $788(17.1)$ & 0.041 & $69(15.5)$ & $122(16.4)$ & 0.704 \\
\hline $\mathrm{RCA}, \mathrm{N}(\%)$ & $780(27.7)$ & $1,353(29.4)$ & 0.106 & $120(27.0)$ & $222(29.8)$ & 0.307 \\
\hline AHA/ACC type B2/C, N (\%) & $802(28.5)$ & $1,378(30.0)$ & 0.165 & $279(62.8)$ & $478(62.8)$ & 0.995 \\
\hline Coronary calcification, N (\%) & $286(10.2)$ & $530(11.5)$ & 0.066 & $33(7.4)$ & $88(11.8)$ & 0.016 \\
\hline CTO, N (\%) & $0(0.0)$ & $0(0.0)$ & 1.000 & 0 & 0 & 1.000 \\
\hline FFR/IVUS/OCT, N (\%) & $277(9.8)$ & $402(8.7)$ & 0.116 & $89(20.0)$ & $144(19.3)$ & 0.764 \\
\hline Stents number $\geq 2, N(\%)$ & $936(33.2)$ & $1,730(37.6)$ & $<0.001$ & $68(15.3)$ & $119(16.0)$ & 0.763 \\
\hline Total stent length (mm) & $35.29 \pm 20.54$ & $37.50 \pm 21.68$ & $<0.001$ & $37.62 \pm 20.165$ & $40.04 \pm 22.75$ & 0.206 \\
\hline Stent diameter $\geq 2.5 \mathrm{~mm}, \mathrm{~N}(\%)$ & 2,523 (89.6) & $4,107(89.4)$ & 0.782 & $412(92.8)$ & $690(92.6)$ & 0.911 \\
\hline Ballon pre-dilation, N (\%) & $2,408(85.5)$ & $3,942(85.8)$ & 0.730 & $403(90.8)$ & $678(91.0)$ & 0.889 \\
\hline Ballon post-dilation, $\mathrm{N}(\%)$ & $2,586(91.8)$ & 4,181 (91.0) & 0.219 & $439(98.9)$ & $729(97.9)$ & 0.196 \\
\hline
\end{tabular}

Values are expressed as mean \pm SD or $n(\%)$ unless otherwise indicated. NLR, neutrophil to lymphocyte ratio; WBC, white blood cell; PLT, platelet; CRP, C-creative protein; BMI, Body Mass Index; LDL-C, low-density lipoprotein cholesterol; CABG, Coronary Artery Bypass Grafting; MI, myocardial infarction; PCl, percutaneous coronary intervention; ACEI, Angiotensin-Converting Enzyme Inhibitors; ARB, Angiotensin receptor blocker; CCB, Calcium channel blocker; LM, left main; LAD, left anterior descending branch; LCX, left circumflex artery; RCA, right coronary artery; AHA/ACC, American College of Cardiology/American Heart Association; CTO, chronic total occlusion; FFR, Fractional Flow Reserve; IVUS, intravascular ultrasound; OCT, optical coherent tomography. 
Table S3 Baseline characteristics according to WBC levels

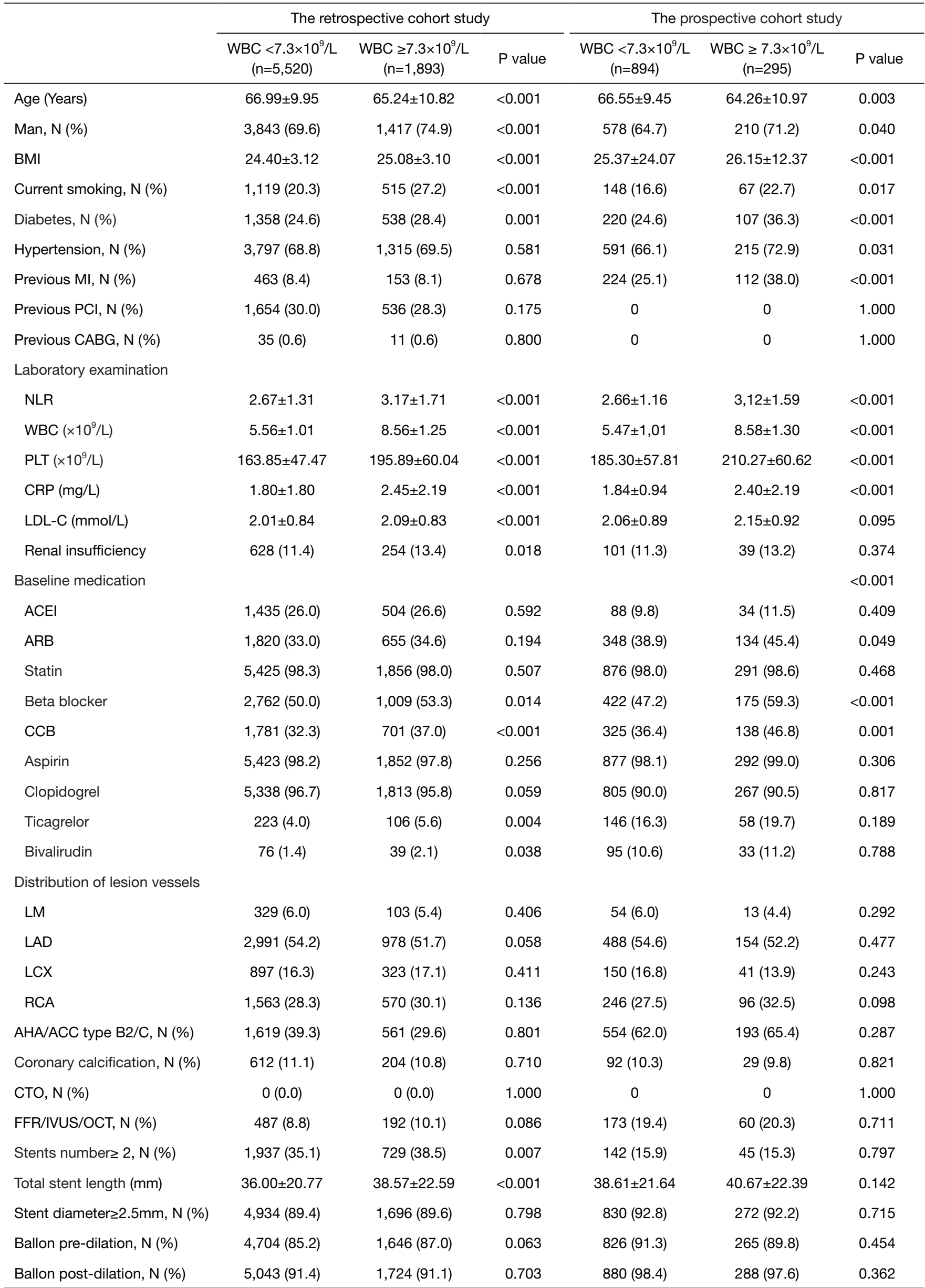

Values are expressed as mean \pm SD or $n(\%)$ unless otherwise indicated. NLR, neutrophil to lymphocyte ratio; WBC, white blood cell; PLT, platelet; CRP, C-creative protein; BMI, Body Mass Index; LDL-C, low-density lipoprotein cholesterol; CABG, Coronary Artery Bypass Grafting; MI, myocardial infarction; PCI, percutaneous coronary intervention; ACEI, Angiotensin-Converting Enzyme Inhibitors; ARB, Angiotensin receptor blocker; CCB, Calcium channel blocker; LM, left main; LAD, left anterior descending branch; LCX, left circumflex artery; RCA, right coronary artery; AHA/ACC, American College of Cardiology/American Heart Association; CTO, chronic total occlusion; FFR, Fractional Flow Reserve; IVUS, intravascular ultrasound; OCT, optical coherent tomography. 
Table S4 Baseline characteristics according to inflammatory trend

\begin{tabular}{|c|c|c|c|}
\hline & I tertile $(n=3,800)$ & II tertile $(n=3,613)$ & $P$ value \\
\hline Age (Years) & $65.86 \pm 9.94$ & $67.25 \pm 10.44$ & $<0.001$ \\
\hline Man, N (\%) & $2,585(68.0)$ & $2,675(74.0)$ & $<0.001$ \\
\hline BMI & $24.37 \pm 3.14$ & $24.78 \pm 3.10$ & $<0.001$ \\
\hline Current smoking, N (\%) & $771(20.3)$ & $863(23.9)$ & $<0.001$ \\
\hline Diabetes, N (\%) & $894(23.5)$ & $1,002(27.7)$ & $<0.001$ \\
\hline Hypertension, N (\%) & $2,507(66.0)$ & $2,605(72.1)$ & $<0.001$ \\
\hline Previous MI, N (\%) & $315(8.3)$ & $301(8.3)$ & 0.948 \\
\hline Previous PCI, N (\%) & $1,188(31.3)$ & $1,002(27.7)$ & 0.001 \\
\hline Previous CABG, N (\%) & $19(0.5)$ & $27(0.7)$ & 0.175 \\
\hline \multicolumn{4}{|l|}{ Laboratory examination } \\
\hline NLR & $2.14 \pm 0.77$ & $3.49 \pm 1.65$ & $<0.001$ \\
\hline WBC $\left(\times 10^{9} / \mathrm{L}\right)$ & $5.41 \pm 1.18$ & $7.30 \pm 1.62$ & $<0.001$ \\
\hline $\operatorname{PLT}\left(\times 10^{9} / \mathrm{L}\right)$ & $162.99 \pm 47.30$ & $181.53 \pm 56.59$ & $<0.001$ \\
\hline CRP (mg/L) & $1.17 \pm 1.16$ & $2.81 \pm 2.20$ & $<0.001$ \\
\hline LDL-C (mmol/L) & $2.00 \pm 0.83$ & $2.06 \pm 0.84$ & $<0.001$ \\
\hline Renal insufficiency, N (\%) & $307(8.1)$ & 575 (15.9) & $<0.001$ \\
\hline \multicolumn{4}{|l|}{ Baseline medication, N (\%) } \\
\hline ACEI & $962(35.3)$ & $977(27.0)$ & 0.091 \\
\hline ARB & $1,192(31.4)$ & $1,283(35.5)$ & $<0.001$ \\
\hline Statin & $3,744(98.5)$ & $3,537(97.9)$ & 0.040 \\
\hline Beta blocker & $1,867(49.1)$ & $1,904(52.7)$ & 0.002 \\
\hline CCB & $1,160(30.5)$ & $1,322(36.6)$ & $<0.001$ \\
\hline Aspirin & $3,737(98.3)$ & $3,538(97.9)$ & 0.183 \\
\hline Clopidogrel & $3,695(97.2)$ & $3,456(95.7)$ & $<0.001$ \\
\hline Ticagrelor & $124(3.3)$ & $205(5.7)$ & $<0.001$ \\
\hline Bivalirudin & $45(1.2)$ & $70(1.9)$ & 0.009 \\
\hline \multicolumn{4}{|l|}{ Distribution of lesion vessels, N (\%) } \\
\hline LM & $212(5.6)$ & $220(6.1)$ & 0.349 \\
\hline LAD & $2,103(55.3)$ & $1,866(51.6)$ & 0.001 \\
\hline LCX & $599(15.8)$ & $621(17.2)$ & 0.098 \\
\hline RCA & $1,057(27.8)$ & $1,076(29.8)$ & 0.062 \\
\hline AHA/ACC type B2/C, N (\%) & $1,101(29.0)$ & $1,079(29.9)$ & 0.400 \\
\hline Coronary calcification, N (\%) & $388(10.2)$ & $428(11.8)$ & 0.025 \\
\hline CTO, N (\%) & $0(0.0)$ & $0(0.0)$ & 1.000 \\
\hline FFR/IVUS/OCT, N (\%) & $361(9.5)$ & $318(8.8)$ & 0.297 \\
\hline Stents number $\geq 2, N(\%)$ & $1,282(33.7)$ & $1,384(38.3)$ & $<0.001$ \\
\hline Total stent length (mm) & $35.15 \pm 20.20$ & $38.24 \pm 22.25$ & $<0.001$ \\
\hline Stent diameter $\geq 2.5 \mathrm{~mm}, \mathrm{~N}(\%)$ & $3,422(90.1)$ & $3,208(88.8)$ & 0.077 \\
\hline Ballon pre-dilation, N (\%) & $3,244(85.4)$ & $3,106(86.0)$ & 0.462 \\
\hline Ballon post-dilation, N (\%) & 3469 (91.3) & 3,298 (91.3) & 0.990 \\
\hline
\end{tabular}

Values are expressed as mean \pm SD or $n(\%)$ unless otherwise indicated. NLR, neutrophil to lymphocyte ratio; WBC, white blood cell; PLT, platelet; CRP, C-creative protein; BMI, Body Mass Index; LDL-C, low-density lipoprotein cholesterol; CABG, Coronary Artery Bypass Grafting; MI, myocardial infarction; PCI, percutaneous coronary intervention; ACEl, Angiotensin-Converting Enzyme Inhibitors; ARB, Angiotensin receptor blocker; CCB, Calcium channel blocker; LM, left main; LAD, left anterior descending branch; LCX, left circumflex artery; RCA, right coronary artery; AHA/ACC, American College of Cardiology/American Heart Association; CTO, chronic total occlusion; FFR, Fractional Flow Reserve; IVUS, intravascular ultrasound; OCT, optical coherent tomography. 
Table S5 Logistics regression of the virtual variable inflammatory trend

\begin{tabular}{|c|c|c|c|c|c|c|c|c|}
\hline \multirow{2}{*}{$\begin{array}{l}\text { Variable } \\
\text { Inflammatory trend }\end{array}$} & \multicolumn{4}{|c|}{ Simple regression } & \multicolumn{4}{|c|}{ Multiple regression } \\
\hline & $\frac{\mathrm{OR}}{1.365}$ & 1.192 & 1.564 & $\begin{array}{c}\mathrm{P} \\
<0.001\end{array}$ & $\frac{\text { OR }}{1.202}$ & 1.042 & 1.387 & $\frac{P}{0.012^{*}}$ \\
\hline Age & 1.025 & 1.018 & 1.032 & $<0.001$ & 1.021 & 1.013 & 1.029 & $<0.001^{\star}$ \\
\hline Man & 0.740 & 0.641 & 0.854 & $<0.001$ & 0.739 & 0.631 & 0.866 & $<0.001^{\star}$ \\
\hline Current smoking & 0.881 & 0.683 & 0.962 & 0.016 & 0.969 & 0.802 & 1.171 & 0.745 \\
\hline Diabetes & 1.157 & 0.995 & 1.346 & 0.059 & & & & \\
\hline Hypertension & 1.448 & 1.240 & 1.629 & $<0.001$ & 1.161 & 0.985 & 1.368 & 0.075 \\
\hline LDL-C $>1.8 \mathrm{mmol} / \mathrm{L}$ & 0.885 & 0.773 & 1.014 & 0.078 & & & & \\
\hline AHA/ACC TypeB2/C & 1.346 & 1.166 & 1.552 & $<0.001$ & 1.150 & 0.989 & 1.338 & $0.070^{*}$ \\
\hline Balloon pre-dilation & 1.334 & 1.082 & 1.645 & 0.007 & 1.161 & 0.933 & 1.445 & 0.181 \\
\hline Balloon post-dilation & 1.784 & 1.332 & 2.388 & $<0.001$ & 1.419 & 1.048 & 1.919 & $0.023^{\star}$ \\
\hline Total stent length (Every 10 mm) & 1.325 & 1.288 & 1.363 & $<0.001$ & 1.312 & 1.275 & 1.351 & $<0.001$ \\
\hline Stent size $>2.5 \mathrm{~mm}$ & 1.067 & 0.852 & 1.335 & 0.141 & & & & \\
\hline
\end{tabular}

Dichotomized values with statistical significance are described in the table. ${ }^{*}, \mathrm{P}<0.05$. NLR, neutrophil to lymphocyte ratio; WBC, white blood cell; PLT, platelet; CRP, C-creative protein; BMI, Body Mass Index; LDL-C, low-density lipoprotein cholesterol; CABG, Coronary Artery Bypass Grafting; MI, myocardial infarction; PCI, percutaneous coronary intervention; ACEI, Angiotensin-Converting Enzyme Inhibitors; ARB, Angiotensin receptor blocker; CCB, Calcium channel blocker; LM, left main; LAD, left anterior descending branch; LCX, left circumflex artery; RCA, right coronary artery; AHA/ACC, American College of Cardiology/American Heart Association; CTO, chronic total occlusion; FFR, Fractional Flow Reserve; IVUS, intravascular ultrasound; OCT, optical coherent tomography.

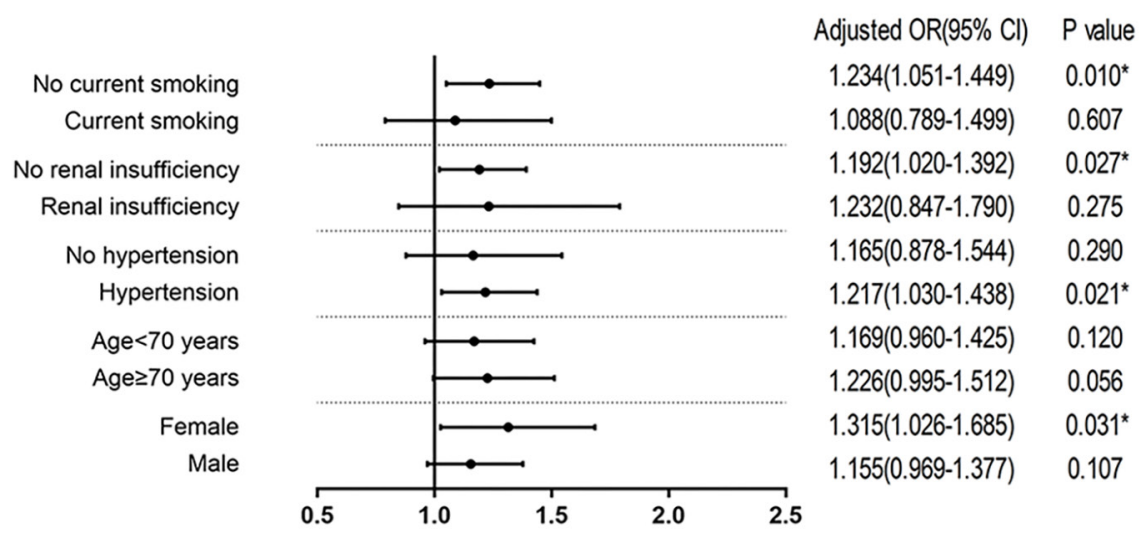

Figure S1 The relationship between inflammatory trend and PMI was analysed by multivariable logistic regression analysis in predefined subgroups. *, $\mathrm{P}<0.05$. PMI, periprocedural myocardial infarction; CRP, C-reactive protein; WBC, white blood cell; NLR, neutrophil to lymphocyte ratio. 